
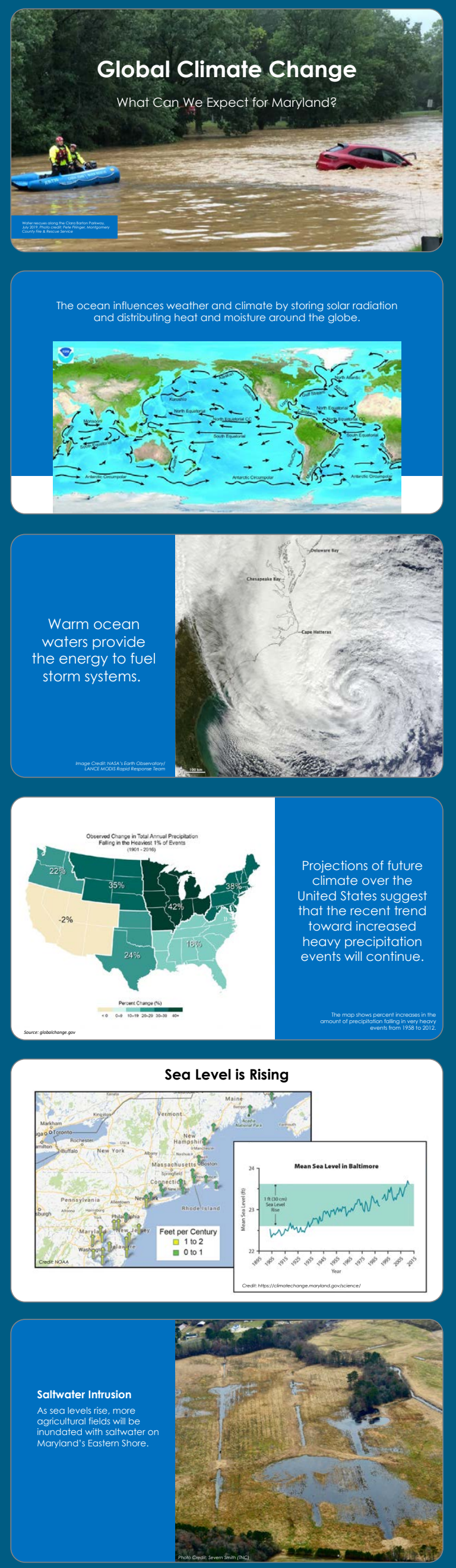

\section{Talking to Local Communities About Climate Change}

As science issues become increasingly important in political and policy debates, it is more important than ever before for scientists to communicate effectively outside the literal and figurative walls of our own communities. In October, I got my opportunity to do just that when I gave a presentation on climate change to attorneys at a Maryland law firm as part of their "continuing legal education" series. Although I'm not a climate scientist, when the invitation arrived I wasn't deterred from accepting. I was confident the Internet contained enough information-in particular, simple explanatory graphics-for me to construct an informative talk.

I wasn't disappointed. There was no perfect one-click download, but US federal and state agencies post a gargantuan amount of information about the causes and consequences of climate change on their websites. Much of the information is aimed directly at educating the public, and much of it is really quite good. The great challenge was to cull the trove of information into a 45-minute talk. I began by covering the workings of the global climate system, and then added a Maryland twist about how global trends translate into problems facing local communities, especially those located along the Atlantic Ocean and in nearby low-lying areas. Not surprisingly, land use and community association lawyers whose clients (or the clients' insurers) worry about future flooding, erosion, and storm intensity were among those most engaged by the presentation, but everyone in the room knew someone whose property is threatened by sea level rise.

Based on my experience, I suggest that our community consider offering a simple and well-designed set of slides and talking points about climate change that can be downloaded from The Oceanography Society website. The presentation would enable any informed person to give a talk on climate change to a small, local group without expending a huge amount of effort. The overarching slide set would provide the big picture of how the global climate system works, with a focus on the ocean's role in it, along with some of the large-scale consequences of global warming. We could perhaps develop add-on slides aimed at specific audiences such as lawyers, real estate developers, or local businesses, or designed to address specific regional issues such as sea level rise or fisheries.

We all know that climate change touches almost every corner of our physical and economic environments, but it was gratifying to see how other professions are anxious to be educated so that they can give the best possible advice about how to adapt, adjust, and cope.

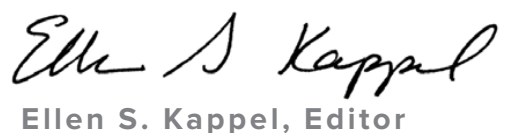

Oceanography | December 2019

5 